\title{
OVER-EXPRESSION OF PARVALBUMIN IN TRANSGENIC MICE RESCUES MOTONEURONS FROM INJURY-INDUCED CELL DEATH
}

\begin{abstract}
J. DEKKERS, ${ }^{a}$ P. BAYLEY, ${ }^{a}$ J. R. T. DICK, ${ }^{a}$ B. SCHWALLER, ${ }^{b}$ M. W. BERCHTOLD ${ }^{\mathrm{c}}$ AND L. GREENSMITH ${ }^{a *}$

a Sobell Department of Motor Neuroscience and Movement Disorders, Institute of Neurology, Queen Square, London WC1N 3BG, UK

${ }^{b}$ Institute of Histology and General Embryology and Program in Neuroscience, University of Fribourg, $\mathrm{CH}-1705$, Switzerland

${ }^{c}$ Department of Molecular Cell Biology, Institute of Molecular Biology, University of Copenhagen, Oster Farimagsgade 2A, DK-1353 Copenhagen, Denmark
\end{abstract}

Abstract-Following nerve injury in neonatal rats, a large proportion of motoneurons die, possibly as a consequence of an increase in vulnerability to the excitotoxic effects of glutamate. Calcium-dependent glutamate excitotoxicity is thought to play a significant role not only in injury-induced motoneuron death, but also in motoneuron degeneration in diseases such as amyotrophic lateral sclerosis (ALS). Motoneurons are particularly vulnerable to calcium influx following glutamate receptor activation, as they lack a number of calcium binding proteins, such as calbindin- $D_{28 \mathrm{k}}$ and parvalbumin. Therefore, it is possible that increasing the ability of motoneurons to buffer intracellular calcium may protect them from cell death and prevent the decline in motor function that usually occurs as a consequence of motoneuron loss. In this study we have tested this possibility by examining the effect of neonatal axotomy on motoneuron survival and muscle force production in normal and transgenic mice that overexpress parvalbumin in their motoneurons.

The sciatic nerve was crushed in one hindlimb of newborn transgenic and wildtype mice. The effect on motoneuron survival was assessed 8 weeks later by retrograde labelling of motoneurons innervating the tibialis anterior muscle. Following nerve injury in wildtype mice, only $20.2 \%( \pm 2.2$, S.E.M.; $n=4$ ) of injured motoneurons survive long term compared with $47.2 \%( \pm 4.4$, S.E.M.; $n=4)$ in parvalbumin overexpressing mice. Surprisingly, this dramatic increase in motoneuron survival was not reflected in a significant improvement in muscle function, since 8 weeks after injury there was no improvement in either maximal twitch and tetanic force, or muscle weights.

Thus, inducing spinal motoneurons to express parvalbumin protects a large proportion of motoneurons from injuryinduced cell death, but this is not sufficient to restore muscle function.

Key words: axotomy, calcium-binding proteins, glutamate excitotoxicity.

*Corresponding author. Tel: +44-0207-837-3611x4280; fax: +440207-813-1673.

E-mail address: I.greensmith.@ion.ucl.ac.uk (L. Greensmith).

Abbreviations: ALS, amyotrophic lateral sclerosis; AMPA, $\alpha$-amino-3hydroxy-5-methyl-4-isoxazolepropionate acid; HRP, horseradish peroxidase.

0306-4522/04

doi:10.1016/j.neuroscience.2003.07.013
Developing rat motoneurons are dependent upon interaction with their target muscle for their survival. Following sciatic nerve injury in neonatal rats a large proportion of motoneurons dies (Lowrie et al., 1982, 1987). However, by 5 days of age, the same injury results in no motoneuron death (Lowrie et al., 1982). Using animal models of motoneuron degeneration, we have previously shown that injured motoneurons are not only more vulnerable to glutamate toxicity (Greensmith et al., 1994a), but can also be rescued from cell death by treatment with glutamate receptor antagonists (Greensmith et al., 1994b), suggesting that glutamate plays a role in injury-induced motoneuron death. In addition, there is evidence that glutamate is involved in the death of motoneurons in diseases such as amyotrophic lateral sclerosis (ALS). ALS is a progressive neurodegenerative disorder that results in the death of motoneurons, eventually leading to muscle weakness and paralysis. Although the cause and mechanism of motoneuron death is not known, it has been hypothesised that the pathogenesis of motoneuron loss involves glutamate-mediated excitotoxicity (Shaw et al., 1997; see Choi, 1988). Indeed, in ALS patients, the only treatment that has been shown to have any therapeutic benefit is the anti-glutamate drug, Riluzole (Bensimon et al., 1994; Lacomblez et al., 1996). This drug is known to block glutamatergic neurotransmission in the CNS by inactivating voltage-dependent sodium channels on glutamatergic nerve terminals (Doble, 1996).

The particular susceptibility of motoneurons to glutamate-mediated damage may be a consequence of several factors. Firstly, the density of the $\alpha$-amino-3-hydroxy-5methyl-4-isoxazolepropionate acid (AMPA) subtype of glutamate receptors on motoneurons has been shown to be high compared with dorsal horn neurons (Vandenberghe et al., 2000a,b). AMPA receptors that do not contain the GluR2 subunit are highly permeable to $\mathrm{Ca}^{2+}$, which makes motoneurons particularly vulnerable to glutamate-mediated damage. Since motoneurons are relatively large cells, this may result in an unusually high influx of $\mathrm{Ca}^{2+}$ into the cell upon stimulation (Vandenberghe et al., 2000a; Greig et al., 2000; Van Den Bosch and Robberecht, 2000). Interestingly, it has also been shown that human motoneurons express atypical $\mathrm{Ca}^{2+}$-permeable AMPA receptors, which may also contribute to the particular vulnerability of motoneurons to excitotoxicity (Williams et al., 1996; Shaw et al., 2000). Furthermore, several studies have shown that motoneurons have a limited ability to buffer intracellular $\mathrm{Ca}^{2+}$ (Palecek et al., 1999). Since glutamate-mediated excitotoxicity is thought to involve $\mathrm{Ca}^{2+}$ accumulation, 
leading to neuronal death (Choi, 1988), the low $\mathrm{Ca}^{2+}$ buffering capacity of motoneurons may render them particularly vulnerable to $\mathrm{Ca}^{2+}$-mediated cell death. Indeed, the distribution of the $\mathrm{Ca}^{2+}$-binding proteins parvalbumin and calbindin- $D_{28 k}$, reflects the selective vulnerability of motoneurons observed in ALS. In this progressive neurodegenerative disorder, motoneurons that do not express these proteins are particularly vulnerable to $\mathrm{Ca}^{2+}$ toxicity following glutamate receptor activation. In contrast, those motoneurons that are largely spared in ALS, such as the oculomotor nuclei and Onuf's nucleus, express these proteins at high levels. It is possible therefore, that these motoneurons are potentially protected from $\mathrm{Ca}^{2+}$-induced cell death by increased $\mathrm{Ca}^{2+}$-buffering properties (Ince et al., 1993; Alexianu et al., 1994; Elliott and Snider, 1995; Reiner et al., 1995).

In this study, we have examined the possibility that the lack of calcium binding proteins may directly contribute to the death of motoneurons after neonatal nerve injury, by studying motoneuron survival in transgenic mice that over-express parvalbumin. These mice have no obvious phenotype, but over-express parvalbumin in neurons of the CNS as well as T cells, the thymus and spleen (Van Den Bosch et al., 2002). Recent results from isolated motoneurons in vitro have shown that spinal motoneurons from these mice are protected from the excitotoxic effects of exogenously applied kainate (Van Den Bosch et al., 2002). In addition, it has also been shown that parvalbumin over-expression in transgenic mice alters immune-mediated increases in intracellular $\mathrm{Ca}^{2+}$ (Beers et al., 2001), resulting in a reduction in the increase of intracellular $\mathrm{Ca}^{2+}$ and spontaneous transmitter release seen after application of ALS immunoglobins when compared with wildtype controls.

In this study, we have examined in vivo, the vulnerability of motoneurons that express parvalbumin to injuryinduced cell death. We have used a well-established animal model of motoneuron degeneration, in which the peripheral nerve is injured at birth, resulting in extensive motoneuron death (Lowrie et al., 1987; Schmalbruch, 1984). The vulnerability of motoneurons to such axotomyinduced cell death was studied in normal and transgenic mice that over-express parvalbumin in their motoneurons, by examining the effect of neonatal sciatic nerve crush on the survival of motoneurons and muscle force production in adult animals.

\section{EXPERIMENTAL PROCEDURES}

\section{Generation of parvalbumin over-expressing mice}

A detailed description of the generation of the parvalbumin overexpressing mice used in this study has been given elsewhere (Van Den Bosch et al., 2002). In brief, these mice contain a transgene consisting of the entire rat parvalbumin coding sequence under the control of the mouse Thy- 1 promoter (Chang et al., 1985; Gotz et al., 1995). Mice are kept as a heterozygous line and are bred to C57BL/6J wildtype mice. Detection of transgenic mice was carried out by PCR using genomic DNA isolated from mouse tail biopsies using rat specific parvalbumin cDNA primers, OL1 5'-CTATATAGGCTCTGACCTCGG-3' and OL2, 5'CAGGGCGTGGTCCTTCGCTC- $3^{\prime}$ as the $5^{\prime}$ and $3^{\prime}$ primers, re- spectively, which produce a PCR product of $669 \mathrm{bp}$. Generally $0.1 \mu \mathrm{g}$ of genomic DNA was used as a template. PCR conditions have been described previously (Castillo et al., 1995).

\section{Surgery}

In these experiments mice (C57BL/6J) of both sexes were used. All efforts were made to minimise animal suffering and the experiments were carried out in accordance with the UK Animals and Scientific procedures Act 1986 . The minimum number of animals needed to produce reliable data was used. One day after birth (P1), the mice were anaesthetised using cold anesthesia, and the sciatic nerve was crushed at the mid-thigh level in one hindlimb. Following recovery from the anesthesia, the pups were returned to their mother. For both morphological and physiological assessment of motoneuron survival a comparison was made between mice that expressed the parvalbumin transgene, and their nonaffected, wildtype littermates.

In order to compare the rate of regeneration of the sciatic nerve from Thy- 1 transgenic and wildtype mice, in some adult mice, the sciatic nerve was crushed in the mid-thigh region using blunt Watchmakers' forceps under halothane anesthesia and sterile conditions. The extent of functional reinnervation of the tibialis anterior (TA) hindlimb muscles was assessed using physiological criteria 14 days after injury.

\section{Immunohistochemistry}

In order to establish that motoneurons in the parvalbumin overexpressing transgenic mice did express parvalbumin, spinal cord sections from mice that carried the transgene and their wildtype littermates were processed for parvalbumin immunohistochemistry at different ages ranging from birth to 8 weeks of age. This was to ensure that parvalbumin was present in motoneurons both at the time of nerve injury (P1), as well as at the time when the effect of injury was assessed ( 8 weeks). The mice were terminally anaesthetised ( $4 \%$ chloral hydrate; $1 \mathrm{ml} / 100 \mathrm{~g}$ body weight, i.p.) and perfused transcardially with a fixative containing $4 \%$ paraformaldehyde. Spinal cord sections were cut at $10 \mu \mathrm{m}$ on a cryostat and thaw-mounted onto gelatinised slides. Sections were blocked using 3\% normal goat serum (Vector Laboratories, Burlingame, CA, USA) for $1 \mathrm{~h}$ and after washing in PBS, a rabbit polyclonal anti-parvalbumin antibody (1: 10,000; Swant, Bellinzona, Switzerland) was applied overnight. The sections were washed, and a biotinylated goat anti-rabbit antibody (Vector) was applied for $2 \mathrm{~h}$. The antibody was visualised using the $A B C$ kit (Vector), using diaminobenzidine.

\section{Retrograde labelling of motoneurons}

Following sciatic nerve crush at P1, motoneurons survival was assessed 8 weeks later by counting the number of retrogradely labelled motoneurons innervating the TA muscles. Under sterile conditions and using halothane anesthesia, horseradish peroxidase (HRP; Type VI; Sigma; Poole, UK) was injected into the TA muscles in both the operated and the unoperated, contralateral control leg $(2 \mu \mathrm{l} / 100 \mathrm{~g}$ body weight; $15 \%$ solution) using a Hamilton microsyringe. Twenty-four hours later the animals were reanaesthetized ( $4 \%$ chloral hydrate; $1 \mathrm{ml} / 100 \mathrm{~g}$ body weight, i.p.), and the animals perfused transcardially with a fixative containing gluteraldehyde (2.5\% in Millonig's phosphate buffer, $\mathrm{pH} 7.3$ ). The spinal cords were removed and postfixed for $2 \mathrm{~h}$ in the same fixative. Following cryoprotection in $30 \%$ sucrose in Millonig's phosphate buffer, frozen sections were cut at $30 \mu \mathrm{m}$. Free-floating sections were processed for HRP histochemistry using a modified Hanker-Yates method (Hanker et al., 1977) and lightly counterstained with a Nissl stain (gallocyanin; Culling, 1963). The number of HRP-labelled motoneurons in the operated and contralateral control ventral horns in each section was counted under a light microscope. In order to prevent the same cell being counted twice 

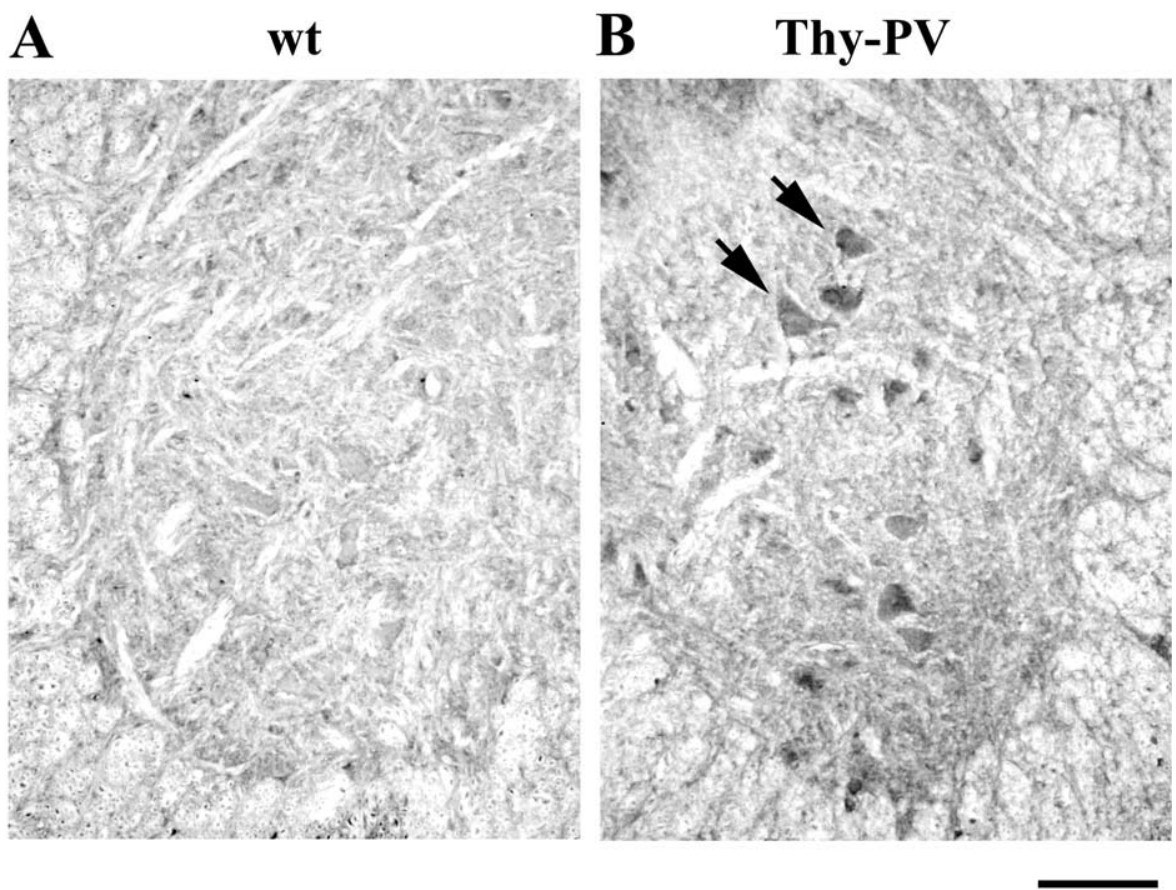

Fig. 1. The figure shows photomicrographs of cross-sections of the ventral horns of spinal cords from adult (A) wildtype and (B) parvalbuminoverexpressing transgenic mice (Thy-PV), stained with an anti-parvalbumin antibody. It can be seen that many motoneuron-like cells in the spinal cord from the parvalbumin transgenic mouse are parvalbumin-immunoreactive (arrows). In contrast, in the wildtype littermates there are no large motoneuron-like cells stained for parvalbumin. Scale bar $=100 \mu \mathrm{m}$.

in consecutive sections, only those neurons in which the nucleolus was clearly visible at high magnification were included in the counts. In addition, the number of surviving motoneurons in the sciatic motor pool was also quantified by counting Nissl-stained motoneurons. When assessing the number of motoneurons revealed with the gallocyanin stain, only the large, polygonal neurons with a distinguishable nucleus and nucleolus and clearly identifiable Nissl structure were counted, as previously described (White et al., 2000). Since all HRP-labelled motoneurons were also clearly counterstained with gallocyanin, they were also included in the Nissl counts. Motoneurons stained with gallocyanin were counted in each ventral horn on alternate sections between the levels of the spinal cord where HRP-labelled motoneurons first appear and when they were no longer present. Therefore, the rostro-caudal position of these cells corresponded mainly to the pool of the common peroneal nerve, but also included motoneurons from other motor pools, for example that of the tibial nerve. In order to provide an index of motoneuron survival for both the retrogradely labelled and Nissl stained motoneurons, for each spinal cord the number of motoneurons on the operated side was expressed as a percentage of the number on the control side. Statistical significance was tested using a $t$-test.

\section{Isometric tension recordings}

Eight weeks after birth, both transgenic animals and their unaffected littermates were anaesthetized with chloral hydrate $(4 \%$ chloral hydrate; $1 \mathrm{ml} / 100 \mathrm{~g}$ body weight, i.p.), and the TA muscle in both the operated and contralateral control hindlimbs was prepared for in vivo assessment of their contractile properties.

The distal tendons of the TA muscles in both limbs were dissected and attached to isometric force transducers (Dynamometer UFI Devices) via silk threads. Both legs were rigidly secured to the table with pins. The sciatic nerve was dissected free, and all its branches, apart from the deep peroneal nerve to the TA muscle were cut. The distal end of the nerve was then stimulated using bipolar silver electrodes. The length of the muscle was adjusted until the maximal twitch was produced upon nerve stimulation. Isometric contractions were elicited by stimulating the motor nerve using $10 \mathrm{~V}$ with a pulse width of $0.02 \mathrm{~ms}$. Tetanic contractions were elicited by stimulating at 40 and $80 \mathrm{~Hz}$ for $550 \mathrm{~ms}$. At the end of the experiment the TA muscles in both the operated and control legs were removed and weighed.

In addition, in a number of adult animals, 14 days after the sciatic nerve had been crushed, the maximal tetanic tension in the TA muscle elicited by stimulating via the sciatic nerve (indirect tension) was compared with that elicited by stimulating the endplate region of the muscle directly (direct tension). The ratio of the direct/indirect tetanic tension indicates the extent of functional innervation of a muscle and in normal muscles this ratio is 1.0 .

\section{RESULTS}

\section{Parvalbumin over-expressing transgenic mice}

Heterozygous animals were mated to C57BL/6J wildtype mice to obtain heterozygous experimental animals. The parvalbumin over-expressing mice had no obvious phenotype and were not distinguishable from their littermates. Therefore, in order to identify individuals expressing the transgene, tail biopsies were taken to provide genomic DNA. In each litter approximately $40 \%$ of the animals carried the parvalbumin transgene.

In order to examine the expression of parvalbumin in the spinal cord of these transgenic mice, parvalbumin immunoreactivity was examined in animals of different ages, ranging from $\mathrm{P} 1$ to adult. Fig. 1 shows examples of spinal cord from adult mice expressing the parvalbumin transgene (Thy-PV), as well as littermates that did not express 
the transgene (wt). In wildtype mice (Fig. 1a), parvalbumin staining was not observed in motoneurons within laminae VIII and IX. Some interneuron-like cells were found to express parvalbumin, which has previously been reported in normal animals in other studies (Celio, 1990). An example of the pattern of parvalbumin-immunoreactivity in the parvalbumin over-expressing mice is shown in Fig. $1 \mathrm{~b}$. Here, motoneurons within the ventral horn are seen to express parvalbumin (Fig. 1b, arrow). This confirms previous findings (Van Den Bosch et al., 2002) that first described the pattern of expression of parvalbumin in these mice, and demonstrates that parvalbumin expression was maintained in motoneurons of adult transgenic mice.

\section{Motoneuron survival following neonatal nerve crush}

The effect of neonatal nerve crush on motoneuron survival was examined 8 weeks after injury. The survival of motoneurons innervating the TA muscle was assessed by counting the number of retrogradely labelled motoneurons in the operated and control ventral horns of each spinal cord. In addition, the survival of motoneurons within the sciatic motor pool was also assessed by counting the number of Nissl-stained motoneurons, using a method described previously (White et al., 2000). An example of a spinal cord section from a wildtype and a transgenic mouse stained for HRP and Nissl, is shown in Fig. 2. The results are summarised in Table 1, which shows that following neonatal nerve injury, only $20.2 \%$ ( \pm 2.2 ; S.E.M., $n=4$ ) of motoneurons innervating the TA muscle survive in wildtype mice 8 weeks later. However, in parvalbumin transgenic mice, $47.2 \%$ ( \pm 4.4 ; S.E.M., $n=4)$ of operated motoneurons survive. Thus, there is a significant increase in the survival of motoneurons innervating the TA muscles in the parvalbumin transgenic mice $(P=0.001 ; t$ test). We also assessed the survival of motoneurons within the sciatic motor pool. As shown in Table 1, in wildtype mice only $38.9 \%$ ( \pm 2.2 ; S.E.M., $n=6$ ) of sciatic motoneurons survived neonatal nerve injury, compared with $60.5 \%( \pm 3.8$; S.E.M., $n=6)$ in parvalbumin transgenic mice. This increase in long-term survival of motoneurons is highly significant $(P=0.001$; $t$-test), and reflects the increase in survival of retrogradely labelled motoneurons, which innervate TA.

\section{Assessment of muscle function following neonatal nerve injury}

Whether the long-term increase in motoneuron survival observed in the parvalbumin transgenic mice was reflected in an improvement in muscle function was also examined. Isometric tension recordings from the TA muscle were carried out in adult animals in which the sciatic nerve had been crushed at 1 day of age. A comparison was made between animals carrying the parvalbumin transgene (Thy-PV) and unaffected littermates (wt).

Following neonatal nerve injury in wildtype mice, there is a considerable and permanent reduction in muscle force and weight. As can be seen in Fig. 3, both the twitch and maximum tetanic tension of TA muscles on the operated side was significantly reduced. Thus, in wildtype control mice the maximum twitch tension was only $37 \%( \pm 4.5$; S.E.M., $n=6$ ) of control and the maximal tetanic tension was only $40.3 \%( \pm 6.5$; S.E.M., $n=6)$ of its contralateral control muscle. In the parvalbumin transgenic mice, although significant numbers of motoneurons survived neonatal nerve injury, this was not reflected in an improvement in muscle force. Thus, in the parvalbumin transgenic mice, the maximal twitch tension of the TA muscle in the operated leg was only $35.3 \%$ ( \pm 2.7 ; S.E.M., $n=6)$ of the contralateral control side and the tetanic tension, $37 \%( \pm 4.5$; S.E.M., $n=6$ ) of control. These results are not significantly different from the maximum tension elicited from the TA muscles in the operated leg of the wildtype control animals.

Following assessment of the muscle force, the operated and control TA muscles were removed and weighed. The results are summarised in Fig. 3. Following neonatal nerve crush, there was a significant reduction in muscle weight, which is evident even in adult animals. Thus, in the wildtype mice, the TA muscle in the operated leg weighed only $33 \%( \pm 2.8$; S.E.M., $n=6)$ of the contralateral control leg. Moreover, there was no difference in the weight of the TA muscle from the operated leg of the parvalbumin positive mice, which weighed only $29 \%( \pm 1.3$; S.E.M., $n=6)$ of the control muscle.

These results show that in parvalbumin over-expressing mice there was a dramatic improvement in the number of motoneurons surviving neonatal nerve injury, compared with their wildtype littermates. However, this increase in motoneuron survival was not reflected in an improvement in the force output of the TA muscle.

\section{Re-innervation of TA muscles following adult nerve injury}

In order to compare the ability of the sciatic nerve from Thy-1 and wildtype animals to re-innervate hindlimb muscles, the ratio of indirect:direct tetanic tension of operated TA muscles was calculated. The results show that in wildtype mice, 14 days after adult sciatic nerve crush, reinnervation is almost complete and the ratio of indirect:direct tension is 0.94 $( \pm 0.008$; S.E.M., $n=3$ ) compared with a ratio of 1.0 in unoperated, contralateral control TA muscles. In Thy- 1 mice there was no evidence that reinnervation of the TA muscles was delayed, and the ration of indirect:direct tension was found to be 1.04 ( \pm 0.02 ; S.E.M., $n=5$ ), indicating that reinnervation of TA is significantly better in the Thy- 1 mice than in wildtype mice $(P=0.036)$.

\section{DISCUSSION}

In this study we have examined the effect of an increase in $\mathrm{Ca}^{2+}$-buffering capacity of motoneurons on their survival, using a well-established injury model of motoneuron degeneration. Our results show that expression of parvalbumin in motoneurons can protect these cells from injuryinduced cell death. Thus, in parvalbumin over-expressing mice, significantly more injured motoneurons survived long term following neonatal sciatic nerve crush, compared with motoneuron survival in littermate control mice. This represents a considerable improvement in the survival of motoneurons, and is likely to be a consequence of the im- 

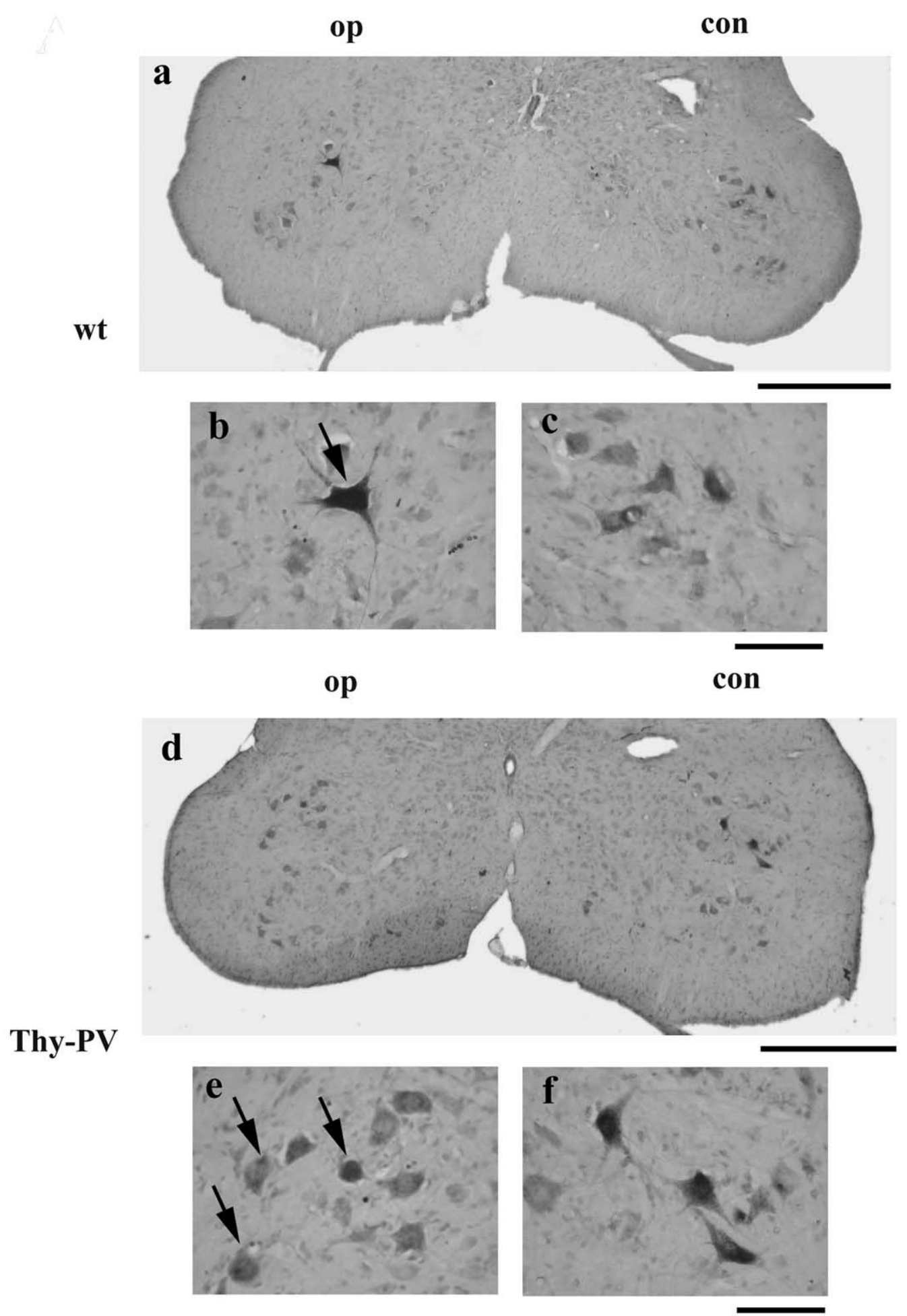

Fig. 2. The figure shows photomicrographs of cross-sections of the lumbar region of the spinal cord from adult mice, in which the sciatic nerve was crushed on one side at P1. Following nerve crush at birth, motoneuron survival was assessed 8 weeks later, by retrograde labelling with HRP of motoneurons innervating the TA muscles in both the operated and control hindlimbs as well as staining of motoneurons in the sciatic motor pool with gallocyanin. For identification the control dorsal horn has been marked with a fine micro-pin. An example of a spinal cord section from a wildtype mouse is shown in (a), where it can be seen that there are fewer HRP-labelled (arrow) motoneurons in the operated ventral horn (b) compared with the control ventral horn (c). There are also significantly fewer Nissl-stained motoneurons in the sciatic motor pool in the operated side. An example of a spinal cord section from a parvalbumin over-expressing littermate is shown in (d). It can be seen that significantly more HRP-labelled (arrows) as well as Nissl stained motoneurons are present in the operated ventral horn of Thy-PV mice (e), than in the operated side of wildtype mice (b). (Scale bars a, $\mathrm{d}=200 \mu \mathrm{m} ; \mathrm{b}, \mathrm{c}, \mathrm{e}, \mathrm{f}=50 \mu \mathrm{m})$. 
Table 1. Motoneuron survival following nerve crush at birth in parvalbumin over-expressing (Thy-PV) and wildtype mice (wt)

\begin{tabular}{|c|c|c|c|c|c|c|}
\hline & \multicolumn{6}{|c|}{ Mean number of motoneurons } \\
\hline & \multicolumn{3}{|l|}{ wt } & \multicolumn{3}{|l|}{ Thy-PV } \\
\hline & $\begin{array}{l}\text { Operated } \\
\text { ventral horn }\end{array}$ & $\begin{array}{l}\text { Control } \\
\text { ventral horn }\end{array}$ & $\%$ Op/con & $\begin{array}{l}\text { Operated } \\
\text { ventral horn }\end{array}$ & $\begin{array}{l}\text { Control } \\
\text { ventral horn }\end{array}$ & $\%$ Op/con \\
\hline HRP, $n=4$ & $35.5 \pm 3.1$ & $176.8 \pm 4$ & $20.2 \pm 2.2$ & $70.3 \pm 11.9$ & $146.3 \pm 13.1$ & $47.2 \pm 4.4$ \\
\hline Nissl, $n=6$ & $179.8 \pm 16.7$ & $457.5 \pm 26.9$ & $38.9 \pm 2.2$ & $258.2 \pm 24.2$ & $423.5 \pm 19.4$ & $60.5 \pm 3.8$ \\
\hline
\end{tabular}

The number of HRP and gallocyanin-stained motoneurons was counted on the operated and control sides of each spinal cord. As an index of motoneuron survival, for each spinal cord, the number of motoneurons present on the operated side was expressed as a percentage of the number on the contralateral control side (\% op/con). All values are mean \pm S.E.M.

proved $\mathrm{Ca}^{2+}$ buffering capacity of motoneurons that express parvalbumin. In these transgenic mice, parvalbumin over-expression is found in the CNS, kidney, thymus and spleen, as well as motoneurons (Van Den Bosch et al., 2002). We have confirmed previous findings, which show that parvalbumin is not normally expressed in motoneurons of wildtype mice (Celio, 1990). However, in parvalbumin transgenic mice, parvalbumin was expressed in large cells, presumably motoneurons, in the ventral horn (see Fig. 1).

Peripheral nerve injury during a critical period of early postnatal development has previously been shown to result in extensive death of motoneurons both in the rat (Romanes, 1946; Lowrie et al., 1987) and the mouse (Pollin et al., 1991). However, the same injury at 5 days of age results in no motoneuron death (Lowrie et al., 1982). This motoneuron degeneration is likely to be mediated via the excitatory neu-

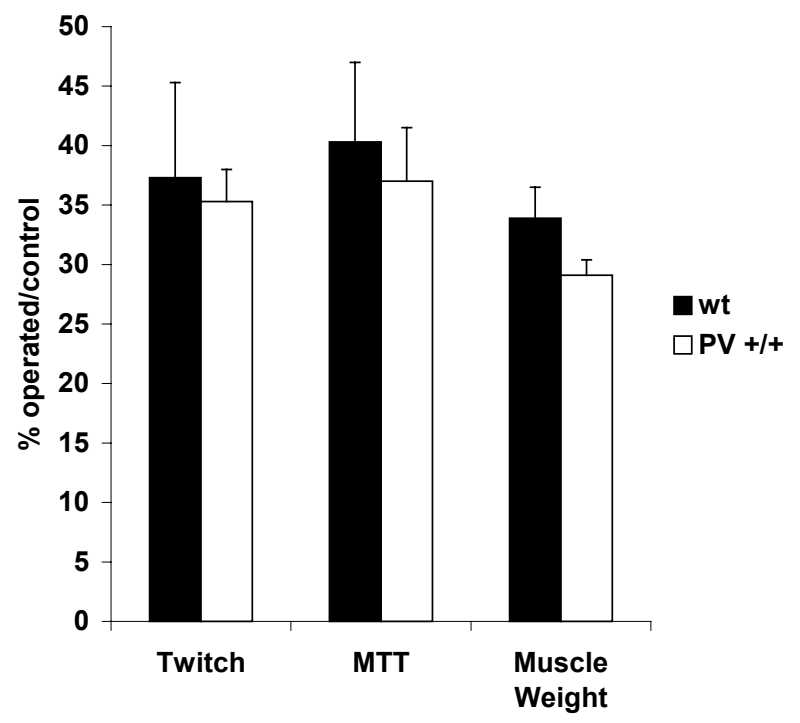

Fig. 3. The bar diagram summarises the results showing the effect of neonatal nerve injury $(\mathrm{P} 1)$ on twitch and tetanic force as well as weight of TA muscles from parvalbumin over-expressing transgenic mice (Thy-PV) and their wildtype (wt) littermates, 8 weeks after injury. The results from TA muscles on the operated side are expressed as a percentage of the control side. The maximal twitch tension was elicited by stimulating the motor nerve using a pulse width of 0.02 and the maximal tetanic tension (MTT) was elicited by stimulating at $80 \mathrm{~Hz}$ for $550 \mathrm{~ms}$. For each parameter assessed there is no significant difference between the values obtained for the wildtype compared with the parvalbumin-overexpressing mice. rotransmitter glutamate (see Williams et al., 1996). Indeed, we have previously shown that injured motoneurons are more vulnerable to glutamate toxicity (Greensmith et al., 1994a), and can be permanently rescued from injury-induced cell death by treatment with glutamate antagonists (Mentis et al., 1993; Greensmith et al., 1994b), with a corresponding improvement in muscle force (Mentis et al., 1993).

Since the activation of glutamate receptors ultimately leads to the influx of $\mathrm{Ca}^{2+}$ into the motoneuron, the ability of the motoneuron to handle $\mathrm{Ca}^{2+}$ may be important in determining the response to stimulation (see Choi, 1992). One important factor that may play a role in determining this response is the $\mathrm{Ca}^{2+}$ buffering capacity of the cell (see Shaw and Ince, 1997). Motoneurons have a relatively low endogenous $\mathrm{Ca}^{2+}$-buffering capacity compared with other neuronal populations (Lips and Keller, 1998, 1999; Palecek et al., 1999) as determined by both quantitative analysis of endogenous $\mathrm{Ca}^{2+}$ buffering capacity and immunocytochemical techniques. Furthermore, disruptions of $\mathrm{Ca}^{2+}$ homeostasis are associated with neuronal degeneration within the CNS. In particular different motoneuron populations show a selective vulnerability to glutamateand $\mathrm{Ca}^{2+}$-mediated neuronal damage (Choi 1988; Rothstein and Kuncl, 1995; Krieger et al., 1996). Although $\mathrm{Ca}^{2+}$-binding proteins such as parvalbumin and calbindin$D_{28 \mathrm{k}}$ do not appear to be expressed by the majority of motoneurons (Alexianu et al., 1994; Ince et al., 1993), those motoneurons that are largely spared in ALS, such as the oculomotor nuclei and Onuf's nucleus, express these proteins at high levels, and are therefore potentially protected by their $\mathrm{Ca}^{2+}$-binding properties (Ince et al., 1993; Alexianu et al., 1994; Elliott and Snider, 1995; Reiner et al., 1995). Accordingly, loading vulnerable motoneurons with exogenous $\mathrm{Ca}^{2+}$ buffers or up-regulating the expression of intrinsic buffers has been suggested as a possible strategy to protect vulnerable motoneurons against neurodegeneration (Alexianu et al., 1994). This approach has recently been tested in a line of parvalbumin over-expressing transgenic mice in which it has been found that parvalbumin expression rescues vulnerable motoneurons from immune-mediated increases in intracellular $\mathrm{Ca}^{2+}$ (Beers et al., 2001). Furthermore, these authors found that parvalbumin expression rescued motoneurons in an animal model of familial ALS. Thus, when parvalbumin transgenic mice are crossed with mutant SOD1 transgenic mice, there is a significant delay in the onset of the disease (Beers et 
al., 2001). In addition, another study has shown that in parvalbumin over-expressing mice, motoneurons in culture are less susceptible to kainate-induced, $\mathrm{Ca}^{2+}$-dependant excitotoxicity (Van Den Bosch et al., 2002). Taken together with the results of the present study, these results provide direct evidence that parvalbumin can have a neuroprotective effect on motoneurons in a variety of models of motoneuron degeneration.

In the present study, we have established that motoneurons induced to express parvalbumin are less vulnerable to injury-induced cell death. However, although more motoneurons survive neonatal axotomy in the parvalbumin transgenic mice, this is not reflected in an improvement in muscle function in these animals. Although this finding is counter-intuitive, there are several possible explanations for this discrepancy. Following nerve crush injury there is a period of denervation of the muscle as the axons of those motoneurons that survive re-grow to innervate the target. Even in the adult, where there is no loss of motoneurons following nerve injury (Vanden Noven et al., 1993), prolonged denervation can result in incomplete recovery of muscle function (Gordon and Fu, 1997), although the shorter the period of denervation, the more complete the recovery of the muscle. Following neonatal nerve injury, which results in extensive motoneuron death, muscles never fully recover even after reinnervation (Lowrie et al., 1982, 1987; Lowrie and Vrbová, 1984; Albani et al., 1988; Murali et al., 1996). After neonatal nerve crush in rats, regenerating axons reach the muscles earlier than in the adult (Murali et al., 1996). Despite this, reinnervated fast muscles become weaker due to the loss of muscle fibers and a proportion of the endplates disintegrate. Fast muscles become more fatigue resistant (Lowrie et al., 1982, 1987; Lowrie and Vrbová, 1984) and the organisation of the motor unit is altered (Albani et al., 1988), although this may be largely due to the loss of motoneurons. It has been suggested that following nerve injury, the period for which the muscle is isolated from the motoneuron, retards the differentiation of the muscle (Lowrie and Vrbová, 1984). During this period of disconnection, motoneurons are still receiving central connexions and continue to develop. Upon reinnervation the muscle fibers may not be mature enough to withstand the pattern of activity imposed upon them by the more mature motoneuron, resulting in further damage to the muscle fibers. This may be particularly true of fast muscles such as TA. Thus, it is clear that neonatal nerve injury can have longlasting deleterious effects on the target muscle.

In the present study, we examined the possibility that the poor recovery of muscle function observed following nerve injury in Thy-1 mice was a consequence of a prolonged period of denervation of the muscles, due to a delay in axonal regeneration. However, it was only possible to carry out these physiological experiments in adult mice following adult nerve injury. The results showed that in Thy-1 mice, over-expression of parvalbumin had no effect on the ability of injured motoneurons to regenerate, since reinnervation of TA 14 days after injury was in fact significantly better than that observed in wildtype mice. However, these experiments were carried out in adult mice, in which motoneurons are known to respond very differently to injury than developing motoneurons. Most importantly, adult motoneurons do not die following injury to their peripheral nerve, although the same insult in neonatal animals results in extensive motoneuron degeneration, and those that survive are permanently altered.

Therefore, it remains possible that regeneration in developing Thy-1 mice following nerve injury is slower than normal, and this may explain the poor recovery of muscle force despite increased motoneuron survival observed in these mice. Thus, in Thy-1 mice, the increased $\mathrm{Ca}^{2+}$ buffering capacity of parvalbumin-expressing motoneurons may alter the spatiotemporal aspects of $\mathrm{Ca}^{2+}$ transients, thereby directly affecting the ability of motoneurons to synthesis proteins required for axonal growth. Following nerve injury the upregulation in the expression of many of the proteins associated with growth, such as tubulin, actin and GAP-43 is mediated by $\mathrm{Ca}^{2+}$ through various second messenger systems (Meiri et al., 1998; Soderling et al., 2001). Increasing the intracellular $\mathrm{Ca}^{2+}$-buffering capacity by inducing parvalbumin expression, may alter the shape of $\mathrm{Ca}^{2+}$ transients, and may therefore have an effect on the ability of the motoneuron to respond to injury by increasing the expression of such growth-associated proteins. This, in turn, could result in reduced or delayed reinnervation. In fast-twitch muscles of transgenic mice in which parvalbumin is knocked out, it has been shown that the initial decay of calcium transients after short $(20 \mathrm{~ms})$ stimulation pulses was significantly slower compared with normal parvalbumin-containing muscles (Schwaller et al., 1999). At the morphological level, the mitochondrial volume in fasttwitch muscles of PV $-I-$ mice was almost doubled compared with muscles of wildtype mice (Chen et al., 2001). Thus, altered parvalbumin expression is possibly linked with the regulation of the synthesis of mitochondrial proteins. Whether parvalbumin over-expression in the transgenic mice examined in this study induces similar mechanisms in developing motoneurons, which are necessary for the regulation of growth-associated proteins is currently being investigated.

In conclusion, the results of this study show that inducing motoneurons to express the calcium binding protein parvalbumin, renders them less susceptible to the effects of neonatal nerve injury. However, there was not a significant improvement in muscle function, illustrating the fact that even though motoneurons in the spinal cord may be spared, the effect of denervation on the target muscle is also vitally important.

Acknowledgements-P.B. is a Wellcome Trust Ph.D. Student. This work was supported by The Sir Samuel Scott of Yews Trust and The Swiss National Science Foundation (grant number: 3100-063448.00/1 to B.S. and 3200-059559.99/1 to M.R.C.). L.G. is the Graham Watts Senior Research Fellow funded by The Brain Research Trust.

\section{REFERENCES}

Albani M, Lowrie MB, Vrbová G (1988) Reorganization of motor units in reinnervated muscles of the rat. J Neurol Sci 88:195-206.

Alexianu ME, Ho BK, Mohamed AH, La Bella V, Smith RG, Appel SH 
(1994) The role of calcium-binding proteins in selective motoneuron vulnerability in amyotrophic lateral sclerosis. Ann Neurol 36:846-858.

Beers DR, Ho BK, Siklos L, Alexianu ME, Mosier DR, Mohamed AH, Otsuka Y, Kozovska ME, McAlhany RE, Smith RG, Appel SH (2001) Parvalbumin over-expression alters immune-mediated increases in intracellular calcium, and delays disease onset in a transgenic model of familial amyotrophic lateral sclerosis. J Neurochem 79:499-509.

Bensimon G, Lacomblez L, Meininger V (1994) A controlled trial of riluzole in amyotrophic lateral sclerosis. ALS/Riluzole Study Group. N Eng J Med 330:585-591.

Castillo MB, Celio MR, Andressen C, Gotzos V, Rulicke T, Berger MC, Weber J, Berchtold MW (1995) Production and analysis of transgenic mice with ectopic expression of parvalbumin. Arc Biochem Biophys 317:292-298.

Celio MR (1990) Calbindin- $D_{28 \mathrm{k}}$ and parvalbumin in the rat nervous system. Neuroscience 35:375-475.

Chang HC, Seki T, Moriuchi T, Silver J (1985) Isolation and characterization of mouse Thy 1 genomic clones. Proc Natl Acad Sci USA 82:3819-23.

Chen G, Carroll S, Racay P, Dick J, Pette D, Traub I, Vrbová G, Eggli P, Celio M, Schwaller B (2001) Deficiency in parvalbumin increases fatigue resistance in fast-twitch muscle and up regulates mitochondria. Am J Physiol Cell Physiol 281:C114-122.

Choi DW (1988) Glutamate neurotoxicity and diseases of the nervous system. Neuron 1:623-634.

Choi DW (1992) Excitotoxic cell death. J Neurobiol 23:1261-1276.

Culling CFA (1963) Handbook of histopathological techniques, 2nd ed. London: Butterworths.

Doble A (1996) The pharmacology and mechanism of action of riluzole. Neurology 47:S233-S241.

Elliott JL, Snider WD (1995) Parvalbumin is a marker of ALS-resistant motor neurons. Neuroreport 6:449-452.

Greensmith L, Hasan HI, Vrbová G (1994a) Nerve injury increases the susceptibility of motoneurons to $N$-methyl-D-aspartate-induced neurotoxicity in the developing rat. Neuroscience 58:727-733.

Greensmith L, Mentis GZ, Vrbová G (1994b) Blockade of N-methyl-Daspartate receptors by MK-801 (dizocilpine maleate) rescues motoneurons in developing rats. Dev Brain Res 81:162-170.

Greig A, Donevan SD, Mujtaba TJ, Parks TN, Rao MS (2000) Characterisation of the AMPA-activated receptors present on motoneurons. J Neurochem 74:179-191.

Gordon T, Fu SY (1997) Long-term response to nerve injury. Adv Neurol 72:185-199.

Gotz J, Probst A, Spillantini MG, Schafer T, Jakes R, Burki K, Goedert M (1995) Somatodendritic localization and hyperphosphorylation of tau protein in transgenic mice expressing the longest human brain tau isoform. EMBO J 14:1304-1313.

Hanker JS, Yates PE, Metz CB, Rustinoni A (1977) A new, specific sensitive and non-carcinogenic reagent for the demonstration of horseradish peroxidase. J Histochem 9:450-455.

Ince PG, Stout N, Shaw PJ, Slade J, Hunziker W, Heizmann CW Baimbridge KG (1993) Parvalbumin and calbindin- $D_{28 k}$ in the human motor system and in motor neuron disease. Neuropathol Appl Neurobiol 19:291.

Krieger C, Lanius RA, Pelech SL, Shaw CA (1996) Amyotrophic lateral sclerosis: the involvement of intracellular $\mathrm{Ca}^{2+}$ and protein kinase C. Trends Pharmacol Sci 17:114-120.

Lacomblez L, Bensimon G, Leigh PN, Guillet P, Meininger V (1996) Dose-ranging study of riluzole in amyotrophic lateral sclerosis: Amyotrophic Lateral Sclerosis/Riluzole Study Group II. Lancet 347: 1425-1431.

Lips MB, Keller BU (1998) Endogenous calcium buffering in motoneurons of the nucleus hypoglossus from mouse. J Physiol 511:105-117.

Lowrie MB, Krishnan S, Vrbová G (1982) Recovery of slow and fast muscles following nerve injury during early postnatal development in the rat. J Physiol 331:51-66.

Lowrie MB, Vrbová G (1984) Differential pattern of recovery of fast and slow muscles following nerve injury in the rat. J Physiol 349:397-410.

Lowrie MB, Krishnan S, Vrbová G (1987) Permanent changes in muscle and motoneurons induced by nerve injury during a critical period of development of the rat. Brain Res Dev Brain Res 31:91-101.

Meiri KF, Saffell JL, Walsh FS, Doherty P (1998) Neurite outgrowth stimulated by neural cell adhesion molecules requires growth-associated protein-43 (GAP-43) function and is associated with GAP-43 phosphorylation in growth cones. J Neurosci 18:10429-10437.

Mentis GZ, Greensmith L, Vrbová G (1993) Motoneurons destined to die are rescued by blocking $N$-methyl-D-aspartate receptors by MK-801. Neuroscience 54:283-285.

Murali DK, Subramaniam K, Vrbová G (1996) Re-innervation of muscles after nerve injury in neonates. Restorative Neurol Neurosci 10:35-42.

Palecek J, Lips M, Keller BU (1999) Calcium dynamics and buffering in motoneurons of the mouse spinal cord. J Physiol 520.2:485-502.

Pollin MM, McHanwell S, Slater CR (1991) The effect of age on motor neurone death following axotomy in the mouse. Development 112 : 83-89.

Reiner A, Medina L, Figueredo-Cardenas G, Anifinson S (1995) Brainstem motoneuron pools that are selectively resistant in amyotrophic lateral sclerosis are preferentially enriched in parvalbumin: evidence from monkey brainstem for a calcium-mediated mechanism in sporadic ALS. Exp Neurol 131:239-250.

Rothstein JD, Kuncl RW (1995) Neuroprotective strategies in a model of chronic glutamate-mediated motor neuron toxicity. J Neurochem 65:643-651.

Romanes GJ (1946) Motor localisation and the effects of nerve injury on the ventral horn cells of the spinal cord. Anatomy 80:117-131.

Schmalbruch $\mathrm{H}$ (1984) Motoneuron death after sciatic nerve section in newborn rats. J Comparative Neurol 224:252-258.

Schwaller B, Dick J, Dhoot G, Carroll S, Vrbová G, Nicotera P, Pette D, Wyss A, Bluethmann H, Hunziker W, Celio MR (1999) Prolonged contraction-relaxation cycle of fast-twitch muscles in parvalbumin knockout mice. Am J Physiol 276:C395-C403.

Shaw PJ, Ince PG (1997) Glutamate, excitotoxicity and amyotrophic lateral sclerosis. J Neurol 244:S3-S14.

Soderling TR, Chang B, Brickley D (2001) Cellular signalling through multifunctional $\mathrm{Ca}^{2+} /$ calmodulin-dependent protein kinase II. J Biol Chem 276:3719-3722.

Vandenberghe W, Robberecht W, Brorson JR (2000a) AMPA receptor calcium permeability, GluR2 expression, and selective motoneuron vulnerability. J Neurosci 20:123-132.

Vandenberghe W, Ihle EC, Patneau DK, Robberecht W, Brorson JR (2000b) AMPA receptor current density, not desensitization, predicts selective motoneuron vulnerability. J Neurosci 20:7158-7166.

Van Den Bosch L, Robberecht W (2000) Different receptors mediate motor neuron death induced by short and long exposures to excitotoxicity. Brain Res Bull 53:383-388.

Van Den Bosch L, Schwaller B, Vleminckx V, Meijers B, Stork S Ruehlicke T, Van Houtte E, Klasses H, Celio MR, Misseaen L, Robberecht W, Berchtold MW (2002) Protective effect of parvalbumin on excitotoxic motor neuron death. Exp Neurol 174:150-161.

Vanden Noven S, Wallace N, Muccio D, Turtz A, Pinter MJ (1993) Adult spinal motoneurons remain viable despite prolonged absence of functional synaptic contact with muscle. Exp Neurol 23:147-156.

Williams TL, Ince PG, Oakley AE, Shaw PJ (1996) An immunocytochemical study of the distribution of AMPA selective glutamate receptor subunits in the normal human motor system. Neuroscience 74:185-198

White CM, Greensmith L, Vrbová G (2000) Repeated stimuli for axonal growth causes motoneuron death in adult rats: the effect of botulinum toxin followed by partial denervation. Neuroscience 95:11011109. 